\title{
Mapping the Minds of Spectators During Extreme Ritual: A Psychological Network Perspective
}

Ronald Fischer ( $\square$ ronald.fischer@vuw.ac.nz)

D'Or Institute for Research and Education

Kemtong Sinwongsuwat

Prince of Songkla University

Punya Tepsing

Prince of Songkla University

Johannes Alfons Karl

Victoria University of Wellington

\section{Research Article}

Keywords: ritual, social bonding, network, authenticity, dysphoria, awe, need for closure

Posted Date: August 11th, 2021

DOI: https://doi.org/10.21203/rs.3.rs-787972/v1

License: (c) (1) This work is licensed under a Creative Commons Attribution 4.0 International License. Read Full License 


\section{Abstract}

Reactions of spectators during extreme rituals raise questions about evolutionary functions of ritual. We computed psychological network models during a large naturally occurring extreme ritual. Our aim is to identify the network structure of psychological reactions to extreme rituals in situ. Participants who observed high ordeal activities ( $N=1,041$ Taoist-Buddhists) completed measures of social, affective, behavioral and uncertainty cognitions. Applying undirected psychometric network models, we found that 1) ritualist cognitions showed a smallworld network structure with highly interconnected nodes, 2) five robust clusters of cognitions that 3 ) can be organized along two major dimensions (positive vs negative valence, uncertainty beliefs vs uncertainty management) and 4) associations between clusters through linking nodes allow integration of previous theories of ritual and help to identify core cognition during ritual. Our study points towards new avenues for evolutionary theory by mapping the interdependence of experienced psychological reactions in situ.

\section{Introduction}

What happens in the minds of people attending large collective rituals? Current theory predicts that rituals regulate a) social connections, b) emotions and c) serve important goals of active participants in ritual, explaining the survival of rituals despite the time and effort costs involved (Hobson et al., 2018; Legare \& Nielsen, 2020). Experimental studies have isolated individual features of rituals and their psychological correlates (Hobson et al., 2017). Significant attention has been paid to the effects of so-called extreme rituals on performers that engage in high ordeal acts, such as fire-walking, blood-letting, or public piercings (Kapitany et al., 2020). These performances have created much discussion about their evolutionary utility and function, given objectives risks and costs for performers (including injury, poisoning, food restriction, etc.) without immediately apparent benefits (Henrich, 2009). Importantly, the majority of participants in widely-performed rituals are not active performers, but observe the performance and may participate by praying or asking for favours from performers (throughout this article we refer to individuals in this role as spectators). Spectators may experience rituals differently (Bulbulia et al., 2013; Fischer et al., 2014), requiring greater attention to the psychological states of spectators. Focusing on spectators who do not engage in central activities of a collective ritual is the first major contribution of our study.

Second, research needs to measure a broader set of psychological reactions in the field, because a) remembered emotions and cognitions may not correspond to psychological states experienced during the ritual (Xygalatas, Schjoedt, et al., 2013), b) rituals may simultaneously affect various psychological states (Boyer \& Liénard, 2020; Hobson et al., 2018) through c) complex and non-linear relations. There is now ample evidence that rituals fulfil three major functions (Hobson et al., 2018):

1) they increase social connection among participants and communities (Reddish et al., 2014, 2016; Xygalatas, Mitkidis, et al., 2013), 
2) they regulate emotions (Atkinson \& Whitehouse, 2011; Fischer et al., 2014; Kapitany et al., 2020; Kavanagh et al., 2019; Páez et al., 2015; Whitehouse et al., 2017) and

3) they modulate task and performance orientations (Gelfand et al., 2020; Mogan et al., 2019; Reddish et al., 2013).

An open question is whether and how these processes may be related. Researchers have tended to focus on one or two selected functions and analysed ritualistic effects in isolation in order to test specific theories. For example, both seminal experiments (Bastian, Jetten, \& Ferris, 2014; Wiltermuth \& Heath, 2009) and longitudinal field studies (Singh et al., 2020; Snodgrass et al., 2017) have demonstrated that ritualistic behaviors increased social connectedness and emotional reactions, but crucially, the associations between these two outcomes of social connectivity and emotional responding were not tested.

Network analyses as recently developed within psychology and related fields are ideal tools for understanding the conceptual relationships between constructs and allow bottom-up insights into the mental representations of individuals. By providing both graphical and statistical insights into the mental maps of experiences, it becomes possible to integrate and extend theory without superimposing ontological relationships onto data using causal models with restrictive assumptions (as commonly applied with latent variable models). Network structures illustrate the 'mental maps' of spectators and how cognitions are statistically linked during a ritual. In a way such networks can be thought of as switchboards showing active connections between cognitions during the ritual which contrasts with typical approaches via regression or experimental studies that test whether a single node is connected to another node (possibly controlling for other node effects, an experimental approach). We advance current understanding of ritual by focusing on a) spectators of a widely celebrated extreme ritual, b) measuring a broader set of emotions and cognitions in situ and c) constructing the network structure of how individual experience and perceive ritual in action; in order to identify more central and peripheral cognitions and advance theorizing about ritualistic functions. Therefore, we shift the focus away from testing isolated theoretical predictions and rather focus on how and how strongly various variables are associated during a collective extreme ritual.

\section{Ritual theories and their conceptual connections}

To briefly outline examples of the reciprocal relationships between the three ritualistic functions across different areas of science, Durkheim's (1995) classic 'collective effervescence' hypothesis of social cohesion involves both emotional dynamics and social connection, with possible complex feedback cycles in which ritualistic behaviour may induce emotional states which strengthen group cohesion or reversely, group cohesion levels facilitate faster spreading of emotional states (Hopkins et al., 2016; Liebst, 2019; Niedenthal \& Brauer, 2012; Páez et al., 2015; van Kleef \& Fischer, 2016). Similarly, social cohesion and performance/goal regulation can be mutually reinforcing by providing feedback on effective cooperation which in turn strengthens social connections (Mogan et al., 2019; Reddish et al., 
2013). Equally, emotion regulation and motor performance reinforce each other (Beatty \& Janelle, 2020; Molden \& Dweck, 2006) (see the outer boxes in Figure 1).

A schematic overview of key processes and mechanisms (cf. Hobson et al., 2017)

Note: The circle connects the three evolutionary salient functions of ritual discussed by Hobson et al. (2017). The three boxes outside the circle describe how the functions may be reciprocally related. The rectangular inner box features three major theoretical approaches (costly signalling, uncertainty management theory, belief/meaning systems as cognitive priors) that may underlie and facilitate the three ritual functions. Table 1 elaborates on the theoretical linkages further.

* this is a simplified statement summarizing the two conditions for the stability of costly rituals (ignoring the public-private ritual distinction for believers vs non-believers; see Sosis, 2003)

What theories could instantiate these three functions (see inner box in Figure 1 \& Table 1)? First, various versions of signalling theory (BliegeBird \& Smith, 2005; Bulbulia \& Sosis, 2011; Sosis, 2003) predict that social coordination is risky (e.g., open to defection \& exploitation), which in turn predicts the emergence of signalling systems that provide information on the trustworthiness of the interaction partners. Second, one core mechanism shaping signalling is existential uncertainty: greater contextual and individual uncertainty increases the need for clearer signals of credibility and trustworthiness (Henrich et al., 2019; Hogg et al., 2010). Costliness of rituals tends to increase with various parameters of uncertainty (Sosis, 2003). Previous studies demonstrated that groups with costly rituals survive longer (Sosis \& Bressler, 2003) and ritual participation increases with higher levels of economic uncertainty (Chen, 2010; Norris \& Inglehart, 2004) and intergroup conflict (Henrich et al., 2019; Sosis et al., 2007). In uncertain

environments, groups offer various tangible and intangible benefits, which increases the risk of freeriders. To deter freeriders, groups raise costly barriers (e.g., rituals) to ensure that only strongly committed individuals join and profit from the group. Hence, benefits from group membership need to outweigh any direct or indirect costs for insiders, but costs need to exceed any benefits for outsiders. In the context of religious ritual, the underlying belief system provides epistemic benefits about the state of the world that are shared by believers but not by outsiders. Current cognitive models suggest that sensory inputs cannot efficiently be processed without well-structured predictive priors (top-down meaning systems) (Clark, 2013; Fischer \& Tasananukorn, 2018). Therefore, meaning systems are not only necessary for understanding and performing ritual, but may also operate as potential benefits, entering the cost-benefit equation of costly signalling (Sosis, 2003). Culturally anchored belief systems serving as shared cognitive priors that structure experiences may reinforce and sustain costly signalling under uncertainty.

Focusing on emotional dynamics, ritual evoke strong emotions. On one hand, Modes theory (Whitehouse, 2004) proposed that rare dysphoric rituals trigger vivid memories which create strong social bonds via shared experiences (Atkinson \& Whitehouse, 2011; Kapitany et al., 2020). In contrast, empirical studies found that emotional reactions are decoupled from memory and physiological states (Bulbulia et al., 2013; Xygalatas, Schjoedt, et al., 2013) and emotional dynamics relate to social connection via collective meaning created around the experience (Hopkins et al., 2016; Livingstone et al., 2011; Páez et 
al., 2015), akin to Durkheim's collective effervescence. In addition, extreme rituals also evoke positive emotional states (Bulbulia et al., 2013; Fischer et al., 2014), resulting in complex patterns of both positive and negative emotional reactions (Atkinson \& Whitehouse, 2011; Kapitany et al., 2020). This raises the question - how are positive and negative emotional processes related when observing extreme rituals? Are emotions dissociated (decoupled) or inversely linked (spectators experiencing either positive or negative states)? This is not a trivial question, especially for more complex emotional experiences such as awe, which is an intense and transformative emotion that involves feeling small and insignificant, and is linked to both positive and negative feelings (Keltner \& Haidt, 2003). Awe can be triggered by experiences that defy everyday explanations (Shiota et al., 2007) common in religious rituals (Valdesolo \& Graham, 2014). Given that awe has been shown to increase social bonding (Nelson-Coffey et al., 2019; Shiota et al., 2007), it begs the question whether experiences of awe relate directly to social connection or whether emotional processes triggered by awe activate social connections. These are some of the yet unaddressed questions that can be tackled via network analyses.

Previous research has focused primarily on (high-ordeal) performers in ritual. What is the role of spectators during extreme ritual? First of all, any high-ordeal performances are only functional if perceived by others, that is socially relevant information is being transmitted about desirable qualities of the performer as well as group relevant information (Henrich, 2009). Without spectators (receivers), there are no signals (Shannon, 1948). Second, this information needs to be decoded, requiring the availability of structured belief systems that allow the efficient decoding of relevant information within the specific social context. Conscious experience requires culturally shared top-down priors that structure and organize sensory input (predictive coding) (Clark, 2013). For a ritual to be maintained it needs to be integrated into a coherent meaning structure and narrative that is shared and understandable by community members. Therefore, participants independent of their role as high-ordeal performer or spectators need to share some basic understanding for the ritual to take place. The typical human reaction to intervene in case of harm (e.g., stopping a performer from piercing their body tissue with a sword) would interfere with the performance of an extreme ritual. Third, meaning systems are learned (Bandura, 1971) and observation of ritual performance is one of the most efficient ways for transmitting culturally shared meaning systems (Rossano, 2012). Fourth, spectators are not passive recipients of information, but are also evaluators of the spectacle. Authenticity and efficacy of ritualistic performance and the supernatural status of the performer are often of major concern for participants (for broader discussions: Chan, 2006; Erekosima \& Eicher, 1981; Wang, 1999): Does the ritual follow culturally validated and consensually recognized forms that mark its performances as correct, true and authentic, therefore marking it as effective (for related work, see Legare \& Souza, 2012)? This fourth point connects our argument back to the first and second point: spectators are participants that through their presence and (emotional and behavioural) reactions validate the ritual performance. Put simply, without spectators there is no spectacle (ritual).

Table 1 presents the core variables and how they are connected to various theories and frameworks of ritual. 
Page $6 / 25$ 


\section{Table 1}

Overview of key variables and theoretical dynamics of relevance for spectators

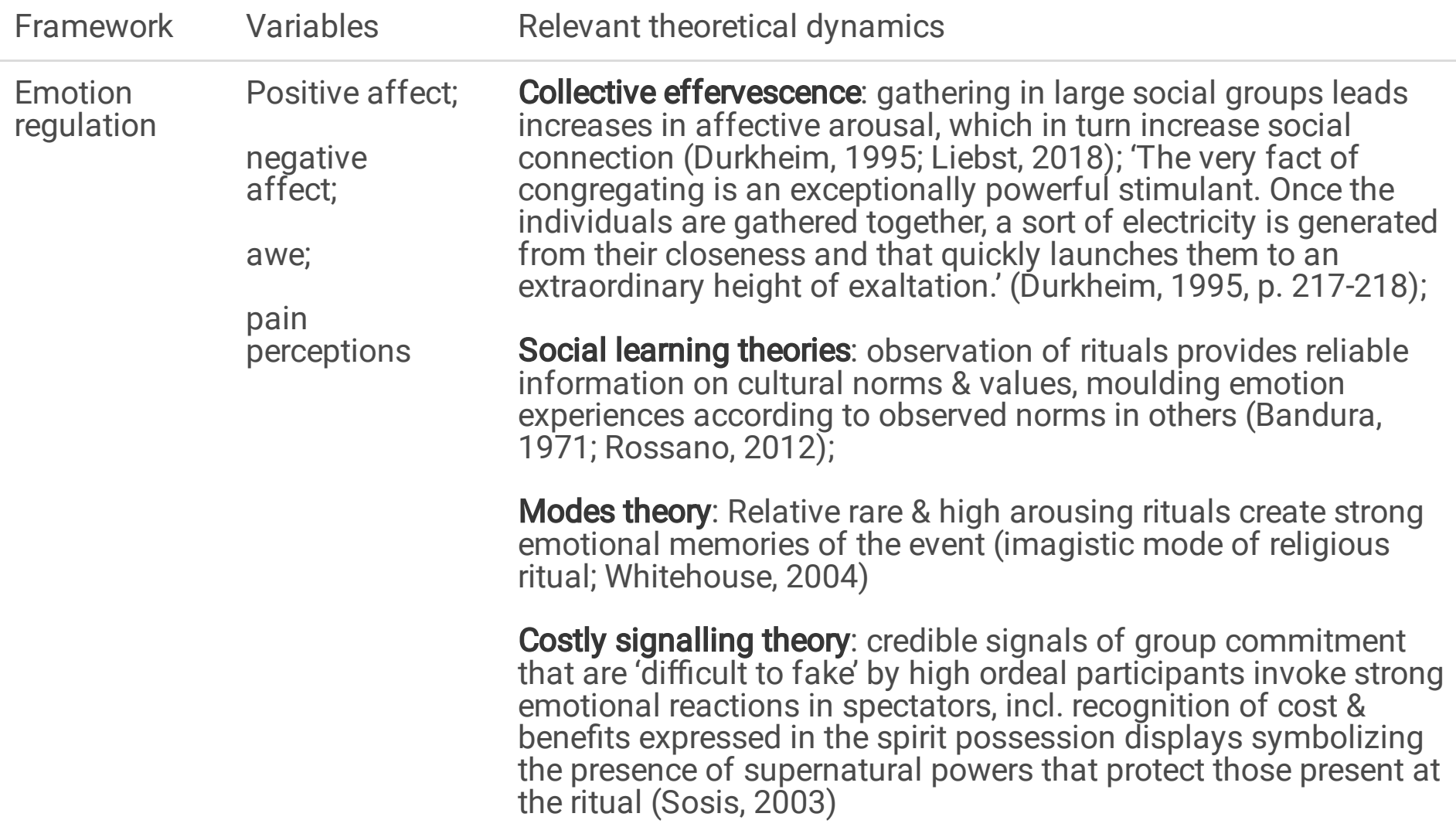

Social Social connection identification with increasing levels of social distance (family/friends; performers; other believers not present);

Identity fusion with highordeal performers \& shrine (institutional context);

Behavioral indicators of commitment to institution \& performers (donations, walking with high-ordeal performers)
Costly signalling theory: credible signals of group commitment that are 'difficult to fake' by high-ordeal participants increase group commitment \& deter free-riders (Sosis, 2003, Singh et al., 2020), these connections should be particularly strong with performers, the institution and other group members

Modes theory: Relative rare \& high arousing rituals create strong social connection through shared memory of participants \& spectators (imagistic mode of religious ritual; Whitehouse, 2004), should increase both social connection \& identify fusion with performers \& other group members

Empathy theory: Social connection to key performers by kinrelated spectators induce stronger emotional sensitivity \& subsequent emotional coupling (Konvalinka et al., 2011), strengthening of linkages between connection to kin \& social group connections 
Performance Behavioral Uncertainty management: ritual participation allows alleviation of Regulation performance regulation petitions to high-ordeal performers to provide blessing, cures, divination, etc. existential uncertainty through confirmation of belief systems \& repetitive actions that capture attention \& modulate emotional arousal (Boyer \& Lienard, 2006; Boyer \& Liénard, 2020; Hogg et al., 2010; Karl \& Fischer, 2018; Lang et al., 2015);

Social learning theory: Observing other group members during the ritual serves as a core learning opportunity for shared cultural norms (including how to behave, what to believe, how to express emotions) (Rossano, 2012)

Meaning \& Uncertainty
Belief systems

of ritualistic efficacy \& authenticity;

Need for closure (uncertainty management)
Uncertainty management theories: Ritual observation decreases existential uncertainty, shared meaning systems in the efficacy \& authenticity of supernatural powers increases the palliative effect of ritual (Boyer \& Lienard, 2020; Henrich et al., 2019, Hogg et al., 2010, Snodgrass et al., 2017);

Costly signalling theories: Belief systems in the benefits of the ritual action shift cost-benefit ratios in favor of ritual participation for believers vs non-believers, the shifts are more pronounced in conditions of uncertainty which require stronger belief \& coherent norms in culturally constructed niches (Bulbulia \& Sosis, 2011; Sosis, 2003);

Predictive coding models of belief: Observing ritual performances $\&$ reactions of other spectators is important for creating shared meaning systems that maintain the cultural system \& help in interpreting the social world (Clark, 2013; Bulbulia \& Sosis, 2011; Fischer \& Tasananukorn, 2018; Rossano, 2012)

In summary, our work focuses on psychological reactions of participants observing an extreme ritual. The key question for our study is - how are experiences and cognitions during rituals related to each other? Previous research typically focused on specific variables in relative isolation - we shift the focus on psychological networks as measured with relevant psychological instruments. A psychological network approach allows us to identify central nodes (variables), their mutual connections (edges) and communities of nodes (clusters) (Costantini et al., 2015; Epskamp et al., 2018), facilitating a more precise identification of core variables within the lived experience of humans and allowing an integration of previously loosely connected theories. We measured variables associated with recently proposed regulatory functions (see Table 1) during a large Buddhist/folk-Daoist ritual attended by over a million spectators annually and which traces its history back to 5,000 year old pre-Chinese Shamanistic practices (Chan, 2006; Cohen, 2001; Fischer \& Kruekaew, 2020). This ritual is one popular expression of folk religions that are widespread throughout Southeast and Southern Asia. Studying a large sample in this non-WEIRD context, the emerging psychological networks ('mental maps') of participants allow us to point towards plausible cognitive mechanisms that may have played a role for the emergence and maintenance of extreme rituals in modern societies, ultimately shining new light on the psychological 
conditions that contribute to an understanding of the emergence of institutions and large-scale civilizations around the world.

\section{Results}

Our network had 31 nodes with 176 non-zero edges out of a total of 465 possible edges (37.8\%), suggesting a reasonably parsimonious network. Of these non-zero edges, 148 were positive (84.1\%). A case-drop bootstrap analysis showed that the edges in our network were stable (edge stability $=.75$ ) and above the recommended threshold of .70 (Epskamp et al., 2018). The smallworldness index which characterizes the overall clustering of the network was 1.14, which is above a threshold of 1 (Humphries \& Gurney, 2008; Watts \& Strogatz, 1998). A small world network implies high clustering and short average path lengths, signalling a highly dense and interconnected psychological network structure with a small number of clusters connected via few key nodes.

In terms of node strength, that is direct links of a node with other nodes weighted by edge importance, 'feeling happy', 'fear', 'believing that spirit mediums care for the welfare of participants', 'believing that spirit mediums have supernatural powers' and 'feeling connected to spirit mediums' were the five most central nodes in the network. This implies that emotional responses and belief in the spirit mediums as well as a strong social connection to the spirit mediums are the most central components of the mental map during the ritual. A bootstrap analysis showed that node strength was stable (see Figure S15). Other node centrality indices (see the supplement) further supported the importance of emotional responses (specifically 'happy' \& 'strong'), beliefs (especially the belief that spirit mediums care for people) and social connection to the spirit mediums and other participants within this cognitive network.

Focusing on the clustering within the network, the EGA analysis found five cluster. Cluster1: consisted of authenticity beliefs, positive emotions and awe, Cluster 2: included social connection (including fusion and social identity), Cluster 3: contained negative emotions and pain, Cluster 4: featured the petition/ritualistic behaviors and Cluster 5: all need for closure items. A bootstrap analysis with 1,000 resamples found five clusters in $32.1 \%$ of the samples, six clusters in $54.1 \%$ of the samples, seven clusters in $11.9 \%$ of the samples and eight clusters in $1.6 \%$. These alternative structures are discussed in the supplement and indicated five clusters as the most coherent and parsimonious solution (see Figure 2).

Dimension 1 captures positive vs negative valence, differentiating positive emotions and belief systems from negative emotion and pain. The second dimension distinguishes uncertainty cognitions (need for closure) at the upper end from behavioral activities that are geared towards managing uncertainty at the lower end (asking for blessings \& advice). Social connection nodes are located within the center of the network, which supports their centrality in overall network. Examining the spatial positioning in a bit more detail, the behavioral items are placed in close proximity to social connection and beliefs. Donations to the shrine and providing support to spirit mediums was positioned near the belief nodes, implying that 
belief and group focused actions are closely related. Family connections were located in proximity with belief and positive emotion, providing some support for previous observations of the importance of family connections within ritual. At the upper end, awe was positioned closest to ambiguity and with links to negative emotions, supporting previous work on the complexity of awe (Shiota et al., 2007).

Examining the most important bridging nodes between communities (top $20 \%$ of the bridging nodes), within the social connection cluster 'feeling connected for family \& friends' (see the size of the shapes in Figure 3; for full details, see Table S6) and 'feeling connected spirit mediums' showed the strongest overall connectedness to other communities. The identity fusion item 'feeling strong because of spirit mediums at the shrine' also had a strong expected influence on other communities. It is noteworthy that these nodes show among the strongest bridge parameters in the network. Focusing on behaviors, donations had the strongest absolute connection with other communities, but 'walking with spirit mediums' during the festival had the strongest positive indirect influence on all other communities. Concerning the emotion-focused clusters, among the positive emotion/authenticity/awe community, the belief that 'mediums care for people' had the strongest absolute connections and indirect influence on other communities. Feeling 'happy' had strong absolute links to other communities, but feeling 'strong' had the strongest positive indirect influence on other network communities. Among the negative emotions cluster, feeling 'sad' was well connected to other communities, but the relative influence was comparatively weak. The uncertainty cluster was relatively weakly connected to other network communities. The node 'like to know what people are thinking' showed the strongest absolute connectivity and relative influence.

\section{Discussion}

Our study maps the cognitions and emotions of spectators in a large extreme ritual attended by more than a million people each year. Sampling responses from over a thousand participants in naturalistic field conditions, we report psychological network representations while observing a ritual. Our findings linking a broader set of cognitions, emotional states and behavioral reports studied across different fields of evolutionary science contribute to a better understanding of how various psychological states are mentally connected in the minds of spectators during ritual (see Table 2).

First, the overall network properties (including smallworldness) suggest that observation of rituals may simultaneously activate various psychological domains and lead to strong connectivity of responses. Recent observations across a range of psychological states and behaviors suggest that small world properties may be relatively common (Fischer \& Karl, 2020; Humphries \& Gurney, 2008). These observations raise important questions about the complex emergent processes during rituals, which may defy experimental isolation of single variable processes.

Second, social connections were centrally located and well connected throughout the network, highlighting the central role of socially focused reactions during ritual among spectators. Signalling theory has focused on the social functions and how high-cost behaviors serve to bind individuals and 
groups (Sosis, 2003). High ordeal acts aligned with beliefs also communicate qualities of the performers (Henrich, 2009). The strongest node connecting the social connection cluster with other cognitions, in particular the adjacent belief cluster, was the feeling of being connected to high performers (spirit mediums). The attention towards and the feeling of being connected to the focal point of the ritual is central for social bonding. The strong links to beliefs that spirit mediums have supernatural power and that supernatural powers are channelled to protect the welfare of all demonstrate implicates belief as a benefit within cost-benefit ratios, supporting social signalling models of costly ritual (Henrich, 2009; Sosis, 2003). Beliefs act as cultural priors that make the world understandable (Clark, 2013). But it is noteworthy that authenticity concerns specifically, and meaning-systems more broadly have received relatively little empirical attention in the evolutionary and experimental study of ritual. Much of the recent focus has been on bottom-up functional features of ritual characteristics such as pain or synchrony that explicitly removed any meaning component (Bastian, Jetten, Hornsey, et al., 2014; Mogan et al., 2017). Literature on costly signalling had clearly foreshadowed the importance of meaning. Both the centrality of behavioral nodes associated with donation behavior and supporting spirit mediums (walking with spirit mediums during the festival) imply signalling effects while beliefs in the benevolent powers of the supernatural agents increase subjective ritualistic benefits. In line with social signalling, belief systems form cultural priors that act as benefits within cognitive networks which reinforce the social connection function of extreme rituals.

Third, the two major dimensions underlying the network are positive vs negative valence and uncertainty cognition vs uncertainty management. The strong differentiation of positively vs negatively valenced cognitions is noteworthy, in particular because many of the core variables that are linked to social connection were closely positioned to positive emotions. Health intervention studies using ritualistic elements (Kok et al., 2013) have demonstrated that induction of positive mood showed strong links with other cognitions and behaviors. These findings highlight the role of positive affect for social bonding and for ritual more broadly (Kapitany et al., 2020). These patterns would not necessarily be expected based on Modes Theory or Costly Signalling models (but see Henrich, 2009 for different perspectives). Possibly arousal rather than valence may be crucial for Mode theory predictions. Furthermore, the observation of key connections in our network, such as the associations of 'feeling strong' point to efficacy and empowerment effects: observing a 'powerful' ritual empowers individuals and strengthens connectedness. Positive emotional processes within ritual clearly deserve greater attention (Xygalatas, 2014).

Fourth, there was a clear secondary dimension differentiating uncertainty concerns (ambiguity) from ritualistic behaviors that are focused on predicting and controlling uncertainty. Behaviors focusing on obtaining blessings, healings or fortune telling were closely connected to social connection and belief clusters, highlighting that uncertainty management mechanisms (Henrich et al., 2019; Hogg et al., 2010) may be tightly coupled with social functions. This is in line with recent observations that every-day behaviors geared towards uncertainty reduction (e.g., prayer) and social dynamics are closely coupled (Fincham \& Beach, 2014). Overall, our patterns suggest that uncertainty management through 
ritual (but not so much uncertainty cognition) is closely associated with social connection dynamics (Henrich et al., 2019).

Finally, awe was part of a positively valenced belief cluster, but was also connected with negative experiences and uncertainty cognitions (especially concerns about thoughts of others). These patterns are in line with the noted complex nature of awe that precluded easy classification into larger emotional systems in recent studies. Extreme rituals invoke strong positive and negative emotional reactions (Kapitany et al., 2020). Experiences of awe during extreme ritualistic performances that defy everyday explanations appear to be the conduit between emotional reactions during ritual which link ritual observation to epistemic needs about certainty. Therefore, our findings point towards awe as a central ritualistic experience that connects belief and emotional reactions.

Table 2

Main findings and implications of the network findings in spectators 
Cognitions

measured during

an extreme ritual

show smallworld

network structures
Cognitions during rituals are highly interconnected, indicating joint activation of various psychological states simultaneously; examination of ritualistic effects in isolation may miss important interdependencies between functions
Five network communities were identified
Two major dimensions underlie the network: a) valence \& $b$ ) uncertainty beliefs vs management
Cognitions during a ritual appear clustered around core psychological functions:

1. belief/positive emotions/awe: clustering of emotional and belief cognitions implying some joint activation of meaning systems and positive emotional responses, highlighting the importance of positive emotional responses and its connection to meaning systems; clustering of awe with beliefs supports the importance of awe for ritual performances (Keltner \& Haidt, 2003; Shiota et al., 2007; Valdesolo \& Graham, 2014);

2. negative emotions \& pain: confirms negative valence of pain displays;

3. Social connection: identity fusion with the shrine $\&$ high ordeal performers, social identification with kin \& other beliefs at the festival and elsewhere show a single cluster, implying that fusion and social connection are closely linked (Bortolini et al., 2018); family ties connect to broader social cognitions (superordinate identity) during ritual (Konvalinka et al., 2011; Singh et al., 2020);

4. Need for closure/ambiguity cognitions (supporting the centrality of uncertainty dynamics);

5. Behavioral clusters: behavioral nodes indicating support for spirit mediums \& shrine merged with behaviors focusing on controlling uncertainty.
Identification of bridging nodes between cluster communities
Uncertainty: Uncertainty is a core organizing principle of cognitions during ritual, separating ambiguity and negative emotional dynamics associated with pain and fear at one end from active behavioral acts that are geared towards controlling uncertainty (asking for advice, blessings \& divination) at the opposite end, supports uncertainty mechanisms for ritual (Henrich et al., 2019; Hogg et al., 2010, Snodgrass et al., 2017).

Valence: a clear distinction of positive vs negatively valenced cognitions is evident, highlighting the emotional complexity of extreme rituals, greater attention to positive valence in particular is needed (Xygalatas, 2014);

Bridging nodes offer insights how activation of cognitions rituals during ritual spreads and therefore may induce greater efficiency of ritual functions: 
(strongest nodes per community):

1. Belief that spirit mediums protect (care); feeling happy, feeling strong, feeling awe;

2. Donating to shrine, walking with spirit mediums;

3. Feeling connected to spirit mediums; feeling connected to family; feeling strong because of mediums (identity fusion);

4. Like to know what other people are thinking;

5. Feeling sad, feeling fear (negative links).
1. Belief nodes that focus on benefits and focus on empowering positive emotions show greater connectivity across communities - supports the importance of belief systems \& empowerment of social emotions (Henrich, 2009; Kok et al., 2013), links of awe to negative emotions \& social connection supports the complexity of awe experiences \& the importance for ritual functioning (Keltner \& Haidt, 2003; Shiota et al., 2007; Valdesolo \& Graham, 2014);

2. Behavioral nodes that signal commitment to the religious system show stronger links throughout the cognitive network, supporting signalling theory (Henrich, 2009; Sosis, 2003);

3. Social connection to both high performers and kin (family) are centrally connected to other cognitions, highlighting the importance of social connection during collective ritual;

4. Epistemic uncertainty, especially concerns about the minds of others are important cognitions that activate \& spread to other cognitions during extreme rituals;

5. Experiencing fear appears to be an important emotional response to extreme displays \& distinguish believers from non-believers; unexpectedly, feeling sad shows some connection to other nodes (may indicate lack of social connection).

\section{Limitations}

The current study was ambitious in measuring variables related to a number of different theoretical accounts in a naturalistic context using a large sample. The conditions of the field study together with low levels of education among some of our participants limited our ability to use more extensive standardized tests or pre-post quasi-experimental designs. At the same time, our scales showed adequate reliabilities and were carefully validated by academic experts and local informants. A major distinguishing point of network analysis is that even single nodes can provide meaningful information in the context of a larger network, making them ideal for mapping complex natural experiences. To increase our understanding of ritual effects, future studies may focus on other high ordeal rituals, such as sports events that involve a high likelihood of accidents or injury (e.g., rugby, mixed martial arts). 


\section{Conclusions}

Ritual are ubiquitous features of all human societies. We focused on mental maps as implied by psychological network structures by spectators: participants who observe a ritual without engaging in high ordeal acts. Our results highlight that 1 ) ritualist cognitions are highly clustered, 2) five robust clusters emerge that 3 ) can be organized along two major dimensions (positive vs negative valence, uncertainty beliefs vs uncertainty management) and 4) associations between clusters allow integration of previous theories of ritual. Ritualistic functions studied in isolation in previous studies are cognitively represented in a highly interconnected 'mental map'.

\section{Methods}

We studied the Nine Emperor God (or Vegetarian) Festival performed by Sino-Thai communities in Southern Thailand. Approximately 10,000 individuals perform these high ordeal acts during the ninth lunar month each year, but close to a million people participate as spectators (for a more detailed ethnographic description, see the supplement, Table S1 and Figures S1-S14). The origins of the festival trace to 5,000 year old pre-Chinese Shaman rituals and variations of these rituals are widespread through South-eastern and Southern Asia (Chan, 2006). Rituals are performed at shrines that involve high ordeal performers (spirit mediums) in trance during which they are believed to receive powerful spiritual warriors and gods. Once in trance, these high ordeal performers perform extreme acts of self-mortification, including cutting, profuse bleeding, piercings to the face and upper body with large objects, burnings, firewalking or sword climbing (see Figures S1-S3). During the rituals, observing participants can ask high ordeal performers to cure ailments, divine the future, protect people, communities and business against evil forces, etc. (see Figures S4-S10).

We collected data in 2015 from 1,041 individuals (Mean age $=30.28, S D=12.48 ; 54.3 \%$ females; $21.7 \%$ with low occupational status [street vendors, cleaners, etc.], $45.6 \%$ of participants occupying governmental or professional jobs). The sample was representative for individuals attending the festival.

There are currently no clear guidelines for power calculations of network models, therefore we aimed to reach comparable sample sizes and variable-to-sample size ratios as used in network tutorials (Costantini et al., 2015). Individuals were approached by local research assistants at various shrines in Kathu and Phuket town on Phuket Island (a traditional centre of the festival) and HatYai (Songkhla province, emerging ritual centre). The largest number of responses were collected from rituals organized by Juitui shrine $(\mathrm{N}=368)$, Kathu shrine ( $\mathrm{N}=364$, both on Phuket island) and Sey Deng shrine in HatYai $(\mathrm{N}=118)$, the remainder was collected at smaller shrines in HatYai. Local research assistants randomly approached potential participants during and immediately after rituals and asked whether they would be willing to participate in a short survey. Participants verbally agreed before they received a survey and returning the completed paper and pencil survey was taken as consent to be included in the study. Some individuals preferred to answer questions in an interview setting (with research assistants reading out the questions). Due to logistics of fieldwork, no records of no-response were collected. All participants were 
Thai nationals and attended the ritual for spiritual purposes. Detailed information on translation and validation procedures are provided in the supplement. Data, material and analytical code are available on the OSF: https://osf.io/wyzbm/?view_only=f345296a3b3c4508adcb1aff109492bf.

\section{Ethics Statement}

The study design has been approved by the School of Psychology Human Ethics Committee under delegated authority of Victoria University of Wellington's Human Ethics Committee (\#0000020925). Informed consent was obtained from all participants prior to participation. All procedures were conducted performed in accordance with the Declaration of Helsinki.

\section{Measured variables}

Social connection. We measured identity fusion with four adapted items (Gómez et al., 2011), see Figure 3 for item content $(a=.92)$. This scale has been used in a variety of contexts (Bortolini et al., 2018; Gomez et al., 2011; Kavanagh et al., 2019) and a visual versions of this scale has been validated for this ritualistic context (Fischer \& Kruekaew, 2020).

Social identity responses were measured by three items measuring social connectedness to different referent groups (Harb \& Smith, 2008). We asked whether individuals felt socially connected (linked) to family and friends; spirit mediums and other believers that are not present at the moment $(a=.71)$.

Emotional responses. Affect was measured with a total of seven items adapted from the Positive and Negative Affect Scale (Watson et al., 1988; Thai version by Boonyarit et al., 2013) and aesthetic experiences scale (Zentner et al., 2008), using a five-point Likert scale. Positive affect (four items, $a=.84$ ) and negative affect (three items, $a=.81$ ) showed good reliability. Awe was measured with two items, asking spectators to indicate how much they felt 'awe' at the ritual today and whether they 'felt small and insignificant today'. A Visual Analog Scale anchored by 0 (no pain) and 10 (worst pain imaginable) was used to measure both subjective pain and perceived pain in spirit mediums (Xygalatas, Mitkidis, et al., 2013).

Meaning-systems \& Uncertainty Management. Authenticity and efficacy beliefs were measured with four items, adapted from Morhart et al. (2015) and Napoli et al. (2014) based on extensive field work by the first and second author (see Figure $3, a=.89$ ).

We adapted four items from the ambiguity subscale of the Revised need for closure scale (Roets \& Van Hiel, 2011), which were measured on a five point scale from 0 to $4(a=.78)$.

Behavioral indicators. To measure behaviours related to performance regulation, we asked respondents yes/no questions on whether they had consulted a) spirit mediums (high ordeal performers) during the Vegetarian Festival, b) at other occasions outside the Vegetarian Festival and c) whether the respondent had placed a table outside his home or business to receive the blessings of spirit mediums (high ordeal performers). For behaviors indicating social connection, we asked whether the spectator had walked with 
the spirit medium and whether the spectator had donated money to the shrine. Items were based on previous ethnographic work (Cohen, 2001; Fischer \& Kruekaew, 2020).

\section{Analytical Strategy}

We computed an undirected network which is ideally suited to uncover possible relationships between constructs in observational research (Costantini et al., 2015; Epskamp et al., 2018; Golino et al., 2020). A network maps observed indicators such as items in a survey as nodes and the relationship with other nodes as edges. More information on our network models are included in the supplement.

We report the smallworldness index (Humphries \& Gurney, 2008; Watts \& Strogatz, 1998) which provides an index of the overall clustering of the network. We report centrality strength which is the sum of the absolute values of the weights on the edges connected to a node and can be interpreted as a measure of overall connectedness within the network. We tested the stability of the network as well as the centrality indices via non-parametric bootstrapping using both node and case-wise dropping bootstraps (1000 replications for each run). The full results and additional information are available in the supplement.

We tested the distinctiveness of network clusters with bootstrapped Exploratory Graph Analysis (Epskamp \& Fried, 2018) using 1,000 bootstrap samples and a walktrap algorithm (Yang et al., 2016). This method is superior to other methods for identifying optimal number of clusters (Golino et al., 2020). Full results on the both the stability and loading patterns are available in the supplement. To enhance interpretation of the results, we conducted a multidimensional scaling analysis assuming ordinal data on the network data and used the resulting coordinates to plot the EGA network solution. This representation allows a direct interpretation of node distances.

We calculated the extent to which individual nodes within EGA communities link to other nodes in other communities (Jones et al., 2019). We report Bridge strength, which is calculated as the sum of the absolute value of all edges that exist between a specific node within a community and all nodes that are not in the same community as the focal node. In other words, it reports which node within a network community is most strongly connected overall to any other communities within the network. We also report Bridge expected influence (2-step), which includes both direct and indirect effects that a given node within a community has with other communities, either directly (e.g., node $1 \rightarrow$ node 3 ) or indirectly through other nodes (e.g., node 1 -> node 2 -> node 3 ). Bridge expected influence accounts for the direction of the effect. For example, a specific negative mood (sadness) may decrease positive feelings (happiness) but also activate nodes within in a social connection cluster (feel closer to friends \& family). Therefore, bridge network statistics can provide important information on the important nodes that connect network communities.

\section{Declarations}

Due to technical limitations, Declarations section is not available for this version. 


\section{References}

1. Atkinson, Q. D., \& Whitehouse, H. (2011). The cultural morphospace of ritual form. Evolution and Human Behavior, 32(1), 50-62. https://doi.org/10.1016/j.evolhumbehav.2010.09.002

2. Bandura, A. (1971). Social Learning Theory. General Learning Press.

3. Bastian, B., Jetten, J., \& Ferris, L. J. (2014). Pain as social glue: Shared pain increases cooperation. Psychological Science, 25(11), 2079-2085. https://doi.org/10.1177/0956797614545886

4. Bastian, B., Jetten, J., Hornsey, M. J., \& Leknes, S. (2014). The positive consequences of pain: A biopsychosocial approach. Personality and Social Psychology Review, 18(3), 256-279. https://doi.org/10.1177/1088868314527831

5. Beatty, G. F., \& Janelle, C. M. (2020). Emotion regulation and motor performance: An integrated review and proposal of the Temporal Influence Model of Emotion Regulation (TIMER). International Review of Sport and Exercise Psychology, 13(1), 266-296. https://doi.org/10.1080/1750984X.2019.1695140

6. BliegeBird, R., \& Smith, E. (2005). Signaling Theory, Strategic Interaction, and Symbolic Capital. Current Anthropology, 46(2), 221-248. JSTOR. https://doi.org/10.1086/427115

7. Boonyarit, I., Chuawanlee, W., Macaskill, A., \& Supparerkchaisakul, N. (2013). A psychometric analysis of the workplace forgiveness scale. Europe's Journal of Psychology, 9(2), 319-338. https://doi.org/10.5964/ejop.v9i2.551

8. Bortolini, T., Newson, M., Natividade, J. C., Vázquez, A., \& Gómez, Á. (2018). Identity fusion predicts endorsement of pro-group behaviours targeting nationality, religion, or football in Brazilian samples. British Journal of Social Psychology, 57(2), 346-366. https://doi.org/10.1111/bjso.12235

9. Boyer, P., \& Lienard, P. (2006). Why ritualized behavior? Precaution systems and action parsing in developmental, pathological and cultural rituals. In BEHAVIORAL AND BRAIN SCIENCES (Vol. 29, Issue 6, p. 595+). CAMBRIDGE UNIV PRESS. https://doi.org/10.1017/S0140525X06009332

10. Boyer, P., \& Liénard, P. (2020). Ingredients of 'rituals' and their cognitive underpinnings. Philosophical Transactions of the Royal Society B: Biological Sciences, 375(1805), 20190439. https://doi.org/10.1098/rstb.2019.0439

11. Bulbulia, J., \& Sosis, R. (2011). Signalling theory and the evolution of religious cooperation. Religion, 41(3), 363-388. https://doi.org/10.1080/0048721X.2011.604508

12. Bulbulia, J., Xygalatas, D., Schjoedt, U., Fondevila, S., Sibley, C., \& Konvalinka, I. (2013). Images from a jointly-arousing collective ritual reveal affective polarization. Frontiers in Psychology, 4, 960. https://doi.org/10.3389/fpsyg.2013.00960

13. Chan, M. (2006). Ritual is theatre, theatre is ritual: Tang-ki, Chinese spirit medium worship. Wee Kim Wee Centre, Singapore Management University: SNP Reference.

14. Chen, D. L. (2010). Club Goods and Group Identity: Evidence from Islamic Resurgence during the Indonesian Financial Crisis. Journal of Political Economy, 118(2), 300-354.

https://doi.org/10.1086/652462 
15. Clark, A. (2013). Whatever next? Predictive brains, situated agents, and the future of cognitive science. Behavioral and Brain Sciences, 36(3), 181-204.

https://doi.org/10.1017/S0140525X12000477

16. Cohen, E. (2001). The Chinese Vegetarian Festival in Phuket. Religion, ethnicity and tourism on a Southern Thai Island. White Lotus Press.

17. Costantini, G., Epskamp, S., Borsboom, D., Perugini, M., Mõttus, R., Waldorp, L. J., \& Cramer, A. O. J. (2015). State of the aRt personality research: A tutorial on network analysis of personality data in R. Journal of Research in Personality, 54, 13-29. https://doi.org/10.1016/j.jrp.2014.07.003

18. Durkheim, E. (1995). Elementary forms of the religious life (K. E. Fields, Trans.). Free Press.

19. Epskamp, S., Borsboom, D., \& Fried, E. I. (2018). Estimating psychological networks and their accuracy: A tutorial paper. Behavior Research Methods, 50(1), 195-212. https://doi.org/10.3758/s13428-017-0862-1

20. Epskamp, S., \& Fried, E. I. (2018). A tutorial on regularized partial correlation networks. Psychological Methods, 23(4), 617-634. https://doi.org/10.1037/met0000167

21. Erekosima, T. V., \& Eicher, J. B. (1981). Kalabari cut-thread and pulled-thread cloth: An example of cultural authentication. African Arts, 14(2), 48-51.

22. Fincham, F. D., \& Beach, S. R. H. (2014). I say a little prayer for you: Praying for partner increases commitment in romantic relationships. Journal of Family Psychology, 28(5), 587-593. https://doi.org/10.1037/a0034999

23. Fischer, R., \& Karl, J. A. (2020). The network architecture of individual differences: Personality, reward-sensitivity, and values. Personality and Individual Differences, 160(1), 109922. https://doi.org/10.1016/j.paid.2020.109922

24. Fischer, R., \& Kruekaew, J. (2020). Synchrony vs. Pain in males and females: An examination of differential effects on social bonding in a naturally occurring ritual. Religion Brain \& Behavior, 10(4), 407-427. https://doi.org/10.1080/2153599X.2019.1626271

25. Fischer, R., \& Tasananukorn, S. (2018). Altered States of Consciousness, Spirit Mediums, and Predictive Processing; A Cultural Cognition Model of Spirit Possession. Journal of Consciousness Studies, 25(11-12), 179-203.

26. Fischer, R., Xygalatas, D., Mitkidis, P., Reddish, P., Tok, P., Konvalinka, I., \& Bulbulia, J. (2014). The firewalker's high: Affect and physiological responses in an extreme collective ritual. PLOS ONE, 9(2), e88355. https://doi.org/10.1371/journal.pone.0088355

27. Foygel, R., \& Drton, M. (2010). Extended Bayesian information criteria for Gaussian graphical models. Proceedings of the 23rd International Conference on Neural Information Processing Systems Volume 1, 604-612.

28. Gelfand, M. J., Caluori, N., Jackson, J. C., \& Taylor, M. K. (2020). The cultural evolutionary trade-off of ritualistic synchrony. Philosophical Transactions of the Royal Society B: Biological Sciences, 375(1805), 20190432. https://doi.org/10.1098/rstb.2019.0432 
29. Golino, H., Shi, D., Christensen, A. P., Garrido, L. E., Nieto, M. D., Sadana, R., Thiyagarajan, J. A., \& Martinez-Molina, A. (2020). Investigating the performance of exploratory graph analysis and traditional techniques to identify the number of latent factors: A simulation and tutorial. Psychological Methods, 25(3), 292-320. https://doi.org/10.1037/met0000255

30. Gómez, Á., Brooks, M. L., Buhrmester, M. D., Vázquez, A., Jetten, J., \& Swann, W. B. (2011). On the nature of identity fusion: Insights into the construct and a new measure. Journal of Personality and Social Psychology, 100(5), 918-933. https://doi.org/10.1037/a0022642

31. Gomez, A., Brooks, M. L., Buhrmester, M. D., Vazquez, A., Jetten, J., \& Swann, W. B., Jr. (2011). On the nature of identity fusion: Insights into the construct and a new measure. In Journal of Personality and Social Psychology (Vol. 100, Issue 5, pp. 918-933). AMER PSYCHOLOGICAL ASSOC. https://doi.org/10.1037/a0022642

32. Harb, C., \& Smith, P. B. (2008). Self-Construals Across Cultures: Beyond IndependenceInterdependence. Journal of Cross-Cultural Psychology, 39(2), 178-197. https://doi.org/10.1177/0022022107313861

33. Henrich, J. (2009). The evolution of costly displays, cooperation and religion: Credibility enhancing displays and their implications for cultural evolution. In EVOLUTION AND HUMAN BEHAVIOR (Vol. 30, Issue 4, pp. 244-260). ELSEVIER SCIENCE INC. https://doi.org/10.1016/j.evolhumbehav.2009.03.005

34. Henrich, J., Bauer, M., Cassar, A., Chytilova, J., \& Purzycki, B. G. (2019). War increases religiosity. In NATURE HUMAN BEHAVIOUR (Vol. 3, Issue 2, pp. 129-135). NATURE PUBLISHING GROUP. https://doi.org/10.1038/s41562-018-0512-3

35. Hobson, N. M., Schroeder, J., Risen, J. L., Xygalatas, D., \& Inzlicht, M. (2018). The psychology of rituals: An integrative review and process-based framework. Personality and Social Psychology Review, 22(3), 260-284. https://doi.org/10.1177/1088868317734944

36. Hogg, M. A., Adelman, J. R., \& Blagg, R. D. (2010). Religion in the face of uncertainty: An uncertaintyidentity theory account of religiousness. Personality and Social Psychology Review: An Official Journal of the Society for Personality and Social Psychology, Inc, 14(1), 72-83. https://doi.org/10.1177/1088868309349692

37. Hopkins, N., Reicher, S. D., Khan, S. S., Tewari, S., Srinivasan, N., \& Stevenson, C. (2016). Explaining effervescence: Investigating the relationship between shared social identity and positive experience in crowds. Cognition \& Emotion, 30(1), 20-32. https://doi.org/10.1080/02699931.2015.1015969

38. Humphries, M. D., \& Gurney, K. (2008). Network 'small-world-ness': A quantitative method for determining canonical network equivalence. PLOS ONE, 3(4), e0002051. https://doi.org/10.1371/journal.pone.0002051

39. Jones, P. J., Ma, R., \& McNally, R. J. (2019). Bridge Centrality: A Network Approach to Understanding Comorbidity. Multivariate Behavioral Research, 1-15. https://doi.org/10.1080/00273171.2019.1614898 
40. Kapitany, R., Kavanagh, C., \& Whitehouse, H. (2020). Ritual morphospace revisited: The form, function and factor structure of ritual practice. In PHILOSOPHICAL TRANSACTIONS OF THE ROYAL SOCIETY B-BIOLOGICAL SCIENCES (Vol. 375, Issues 1805, SI). ROYAL SOC. https://doi.org/10.1098/rstb.2019.0436

41. Karl, J. A., \& Fischer, R. (2018). Rituals, Repetitiveness and Cognitive Load: A Competitive Test of Ritual Benefits for Stress. Human Nature, 29(4), 418-441. https://doi.org/10.1007/s12110-0189325-3

42. Kavanagh, C. M., Jong, J., McKay, R., \& Whitehouse, H. (2019). Positive experiences of high arousal martial arts rituals are linked to identity fusion and costly pro-group actions. In EUROPEAN JOURNAL OF SOCIAL PSYCHOLOGY (Vol. 49, Issue 3, pp. 461-481). WILEY. https://doi.org/10.1002/ejsp.2514

43. Keltner, D., \& Haidt, J. (2003). Approaching awe, a moral, spiritual, and aesthetic emotion. Cognition \& Emotion, 17(2), 297-314. https://doi.org/10.1080/02699930302297

44. Kok, B. E., Coffey, K. A., Cohn, M. A., Catalino, L. I., Vacharkulksemsuk, T., Algoe, S. B., Brantley, M., \& Fredrickson, B. L. (2013). How Positive Emotions Build Physical Health: Perceived Positive Social Connections Account for the Upward Spiral Between Positive Emotions and Vagal Tone. Psychological Science, 24(7), 1123-1132. https://doi.org/10.1177/0956797612470827

45. Konvalinka, I., Xygalatas, D., Bulbulia, J., Schjodt, U., Jegindo, E.-M., Wallot, S., Van Orden, G., \& Roepstorff, A. (2011). Synchronized arousal between performers and related spectators in a firewalking ritual. Proceedings of the National Academy of Sciences, 108(20), 8514-8519. https://doi.org/10.1073/pnas.1016955108

46. Lang, M., Kratky, J., Shaver, J. H., Jerotijevic, D., \& Xygalatas, D. (2015). Effects of Anxiety on Spontaneous Ritualized Behavior. In CURRENT BIOLOGY (Vol. 25, Issue 14, pp. 1892-1897). CELL PRESS. https://doi.org/10.1016/j.cub.2015.05.049

47. Legare, C. H., \& Nielsen, M. (2020). Ritual explained: Interdisciplinary answers to Tinbergen's four questions. Philosophical Transactions of the Royal Society of London. Series B, Biological Sciences, 375(1805), 20190419. https://doi.org/10.1098/rstb.2019.0419

48. Legare, C. H., \& Souza, A. L. (2012). Evaluating ritual efficacy: Evidence from the supernatural. Cognition, 124(1), 1-15. https://doi.org/10.1016/j.cognition.2012.03.004

49. Liebst, L. (2019). Exploring the Sources of Collective Effervescence: A Multilevel Study. Sociological Science, 6, 27-42. https://doi.org/10.15195/v6.a2

50. Livingstone, A. G., Spears, R., Manstead, A. S. R., Bruder, M., \& Shepherd, L. (2011). We feel, therefore we are: Emotion as a basis for self-categorization and social action. Emotion (Washington, D.C.), 11(4), 754-767. https://doi.org/10.1037/a0023223

51. Mogan, R., Bulbulia, J., \& Fischer, R. (2019). Joint Action Enhances Cohesion and Positive Affect, but Suppresses Aspects of Creativity When Combined With Shared Goals. Frontiers in Psychology, 9 , 2790. https://doi.org/10.3389/fpsyg.2018.02790

52. Mogan, R., Fischer, R., \& Bulbulia, J. A. (2017). To be in synchrony or not? A meta-analysis of synchrony's effects on behavior, perception, cognition and affect. Journal of Experimental Social 
Psychology, 72, 13-20. https://doi.org/10.1016/j.jesp.2017.03.009

53. Molden, D. C., \& Dweck, C. S. (2006). Finding “Meaning” in Psychology: A Lay Theories Approach to Self-Regulation, Social Perception, and Social Development. American Psychologist, 61(3), 192-203. https://doi.org/10.1037/0003-066X.61.3.192

54. Nelson-Coffey, S. K., Ruberton, P. M., Chancellor, J., Cornick, J. E., Blascovich, J., \& Lyubomirsky, S. (2019). The proximal experience of awe. PLOS ONE, 14(5), e0216780. https://doi.org/10.1371/journal.pone.0216780

55. Niedenthal, P. M., \& Brauer, M. (2012). Social functionality of human emotion. Annual Review of Psychology, 63, 259-285. https://doi.org/10.1146/annurev.psych.121208.131605

56. Norris, P., \& Inglehart, R. (2004). Sacred and Secular: Religion and Politics Worldwide (1st ed.). Cambridge University Press. https://doi.org/10.1017/CBO9780511791017

57. Páez, D., Rimé, B., Basabe, N., Wlodarczyk, A., \& Zumeta, L. (2015). Psychosocial effects of perceived emotional synchrony in collective gatherings. Journal of Personality and Social Psychology, 108(5), 711-729. https://doi.org/10.1037/pspi0000014

58. Reddish, P., Bulbulia, J., \& Fischer, R. (2014). Does synchrony promote generalized prosociality? Religion, Brain \& Behavior, 4(1), 3-19. https://doi.org/10.1080/2153599X.2013.764545

59. Reddish, P., Fischer, R., \& Bulbulia, J. (2013). Let's Dance Together: Synchrony, Shared Intentionality and Cooperation. In PLOS ONE (Vol. 8, Issue 8). PUBLIC LIBRARY SCIENCE. https://doi.org/10.1371/journal.pone.0071182

60. Reddish, P., Tong, E. M. W., Jong, J., Lanman, J. A., \& Whitehouse, H. (2016). Collective synchrony increases prosociality towards non-performers and outgroup members. The British Journal of Social Psychology, 55(4), 722-738. https://doi.org/10.1111/bjso.12165

61. Roets, A., \& Van Hiel, A. (2011). Item selection and validation of a brief, 15-item version of the Need for Closure Scale. Personality and Individual Differences, 50(1), 90-94.

https://doi.org/10.1016/j.paid.2010.09.004

62. Rossano, M. J. (2012). The essential role of ritual in the transmission and reinforcement of social norms. Psychological Bulletin, 138(3), 529-549. https://doi.org/10.1037/a0027038

63. Shannon, C. E. (1948). A Mathematical Theory of Communication. Bell System Technical Journal, 27(3), 379-423. https://doi.org/10.1002/j.1538-7305.1948.tb01338.x

64. Shiota, M. N., Keltner, D., \& Mossman, A. (2007). The nature of awe: Elicitors, appraisals, and effects on self-concept. Cognition and Emotion, 21(5), 944-963.

https://doi.org/10.1080/02699930600923668

65. Singh, P., Tewari, S., Kesberg, R., Karl, J. A., Bulbulia, J., \& Fischer, R. (2020). Time investments in rituals are associated with social bonding, affect and subjective health: A longitudinal study of Diwali in two Indian communities. Philosophical Transactions of the Royal Society B: Biological Sciences, 375(1805), 20190430. https://doi.org/10.1098/rstb.2019.0430

66. Snodgrass, J. G., Most, D. E., \& Upadhyay, C. (2017). Religious Ritual Is Good Medicine for Indigenous Indian Conservation Refugees Implications for Global Mental Health. In CURRENT ANTHROPOLOGY 
(Vol. 58, Issue 2, pp. 257-284). UNIV CHICAGO PRESS. https://doi.org/10.1086/691212

67. Sosis, Kress, H. C., \& Boster, J. S. (2007). Scars for war: Evaluating alternative signaling explanations for cross-cultural variance in ritual costs. In Evolution and Human Behavior (Vol. 28, Issue 4, pp. 234-247). ELSEVIER SCIENCE INC. https://doi.org/10.1016/j.evolhumbehav.2007.02.007

68. Sosis, R. (2003). Why arent we all hutterities? Costly signaling theory and religious behavior. In HUMAN NATURE-AN INTERDISCIPLINARY BIOSOCIAL PERSPECTIVE(Vol. 14, Issue 2, pp. 91-127). ALDINE DE GRUYTER DIVISION WALTER DE GRUYTER INC. https://doi.org/10.1007/s12110-0031000-6

69. Sosis, R., \& Bressler, E. (2003). Cooperation and commune longevity: A test of the costly signaling theory of religion. In CROSS-CULTURAL RESEARCH(Vol. 37, Issue 2, pp. 211-239). SAGE PUBLICATIONS INC. https://doi.org/10.1177/1069397103037002003

70. Valdesolo, P., \& Graham, J. (2014). Awe, uncertainty, and agency detection. Psychological Science, 25(1), 170-178. https://doi.org/10.1177/0956797613501884

71. van Kleef, G. A., \& Fischer, A. H. (2016). Emotional collectives: How groups shape emotions and emotions shape groups. Cognition \& Emotion, 30(1), 3-19. https://doi.org/10.1080/02699931.2015.1081349

72. Wang, N. (1999). Rethinking authenticity in tourism experience. Annals of Tourism Research, 26(2), 349-370. https://doi.org/10.1016/S0160-7383(98)00103-0

73. Watson, D., Clark, L. A., \& Tellegen, A. (1988). Development and validation of brief measures of positive and negative affect: The PANAS scales. Journal of Personality and Social Psychology, 54(6), 1063-1070. https://doi.org/10.1037//0022-3514.54.6.1063

74. Watts, D. J., \& Strogatz, S. H. (1998). Collective dynamics of 'small-world' networks. Nature, 393(6684), 440-442. https://doi.org/10.1038/30918

75. Whitehouse, H. (2004). Modes of religiosity: A cognitive theory of religious transmission. AltaMira Press.

76. Whitehouse, H., Jong, J., Buhrmester, M. D., Gómez, Á., Bastian, B., Kavanagh, C. M., Newson, M., Matthews, M., Lanman, J. A., McKay, R., \& Gavrilets, S. (2017). The evolution of extreme cooperation via shared dysphoric experiences. Scientific Reports, 7(1), 44292. https://doi.org/10.1038/srep44292

77. Wiltermuth, S. S., \& Heath, C. (2009). Synchrony and Cooperation. In PSYCHOLOGICAL SCIENCE (Vol. 20, Issue 1, pp. 1-5). SAGE PUBLICATIONS INC. https://doi.org/10.1111/j.1467-9280.2008.02253.x

78. Xygalatas, D. (2014). Ritual and cohesion. What is the place of euphoric arousal? Commentary on $\mathrm{H}$. Whitehouse \& J. A. Lanman, "The Ties that Bind Us: Ritual, Fusion, and Identification." Current Anthropology, 55(6), 689-690.

79. Xygalatas, D., Mitkidis, P., Fischer, R., Reddish, P., Skewes, J., Geertz, A. W., Roepstorff, A., \& Bulbulia, J. (2013). Extreme rituals promote prosociality. Psychological Science, 24(8), 1602-1605. https://doi.org/10.1177/0956797612472910

80. Xygalatas, D., Schjoedt, U., Bulbulia, J., Konvalinka, I., Jegindø, E.-M., Reddish, P., Geertz, A. W., \& Roepstoff, A. (2013). Autobiographical Memory in a Fire-Walking Ritual. Journal of Cognition and 
Culture, 13(1-2), 1-16. https://doi.org/10.1163/15685373-12342081

81. Yang, Z., Algesheimer, R., \& Tessone, C. J. (2016). A comparative analysis of community detection algorithms on artificial networks. Scientific Reports, 6(1), 30750. https://doi.org/10.1038/srep30750

82. Zentner, M., Grandjean, D., \& Scherer, K. R. (2008). Emotions evoked by the sound of music:

Characterization, classification, and measurement. Emotion, 8(4), 494-521.

https://doi.org/10.1037/1528-3542.8.4.494

\section{Figures}

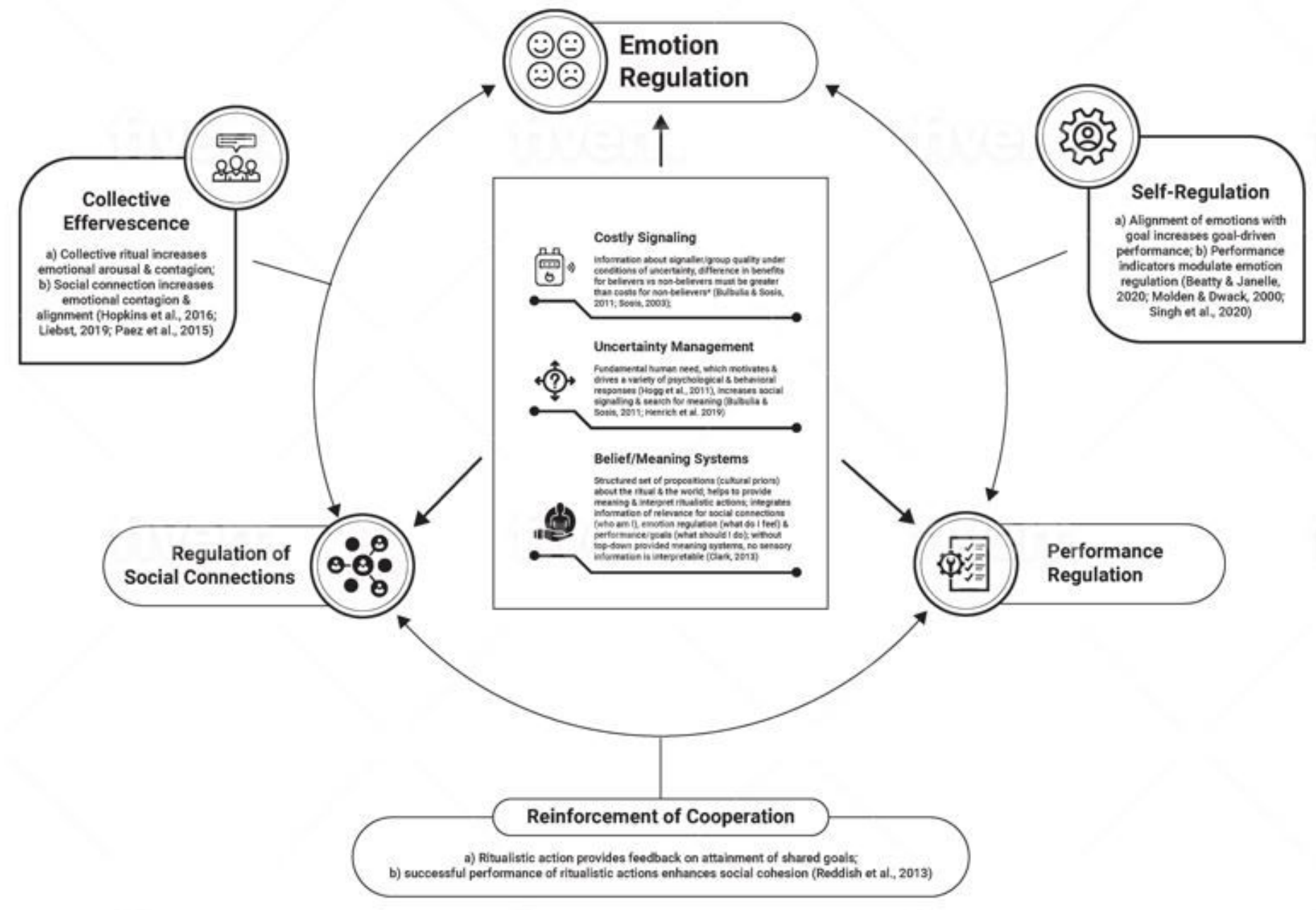

Figure 1

A schematic overview of key processes and mechanisms (cf. Hobson et al., 2017) 


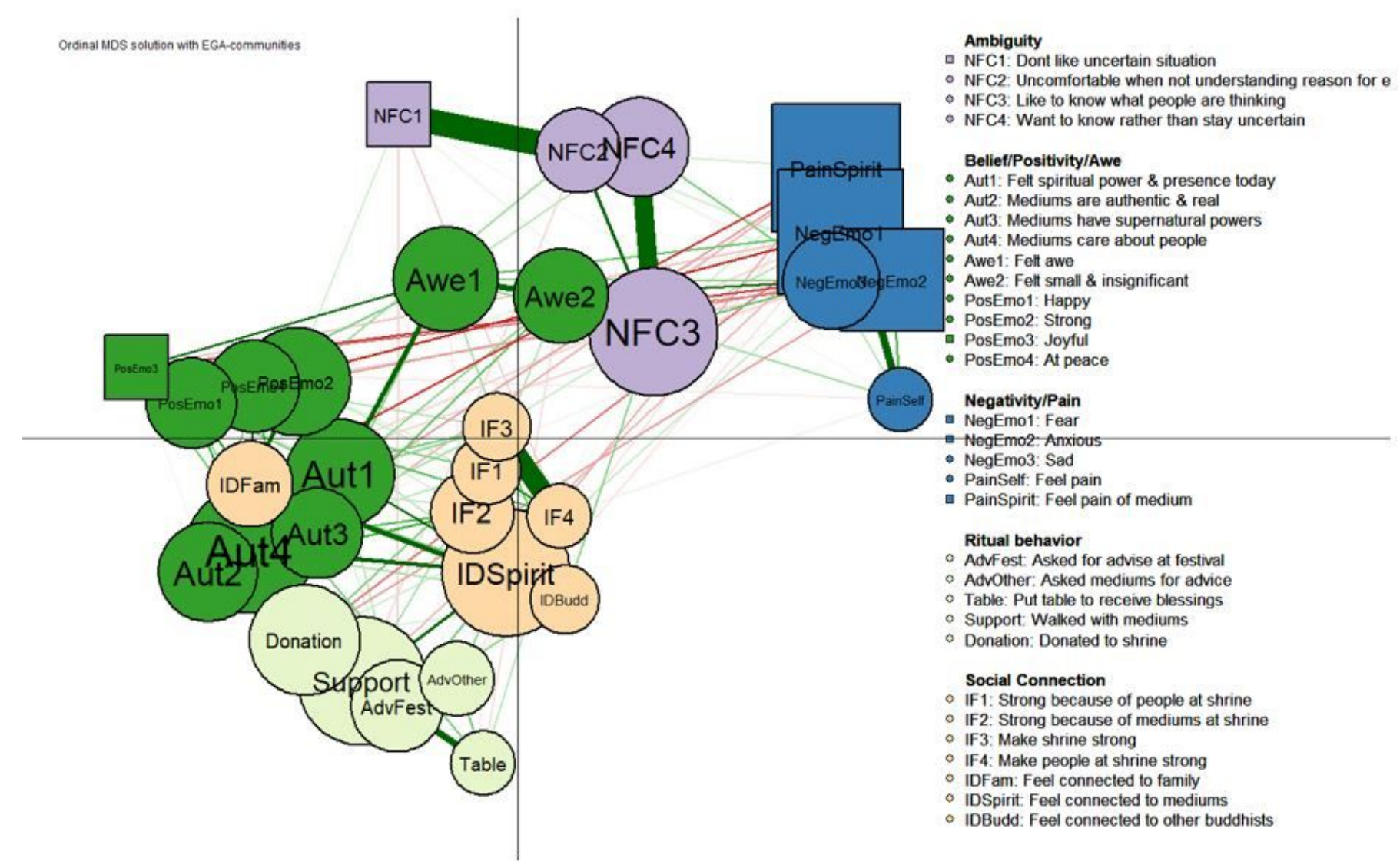

Figure 2

Network structure of psychological reactions during an extreme ritual. Overall network structure based on Extended Bayesian Information Criterion Gaussian Least Absolute Shrinkage and Selection Operator (EBICglasso; Foygel \& Drton, 2010) based network analysis and bootstrapped Exploratory Graph Analysis (EGA) (Epskamp \& Fried, 2018) using a walktrap algorithm (Yang et al., 2016) with 1,000 bootstrap samples. Node colors indicates community membership according to EGA (see the right-hand legend). Node size indicates the expected influence (2-step, including indirect influence) on communities outside the node's community; node shape indicates direction of expected influence (circle - positive, square negative). Green lines indicate positive edges between individual nodes; red edges indicate negative edges between individual nodes. MDS stress $=.13$. For interpretation purposes, the axes are rotated $15^{\circ}$ anticlockwise.

\section{Supplementary Files}

This is a list of supplementary files associated with this preprint. Click to download.

- supplement.revised.july22picturesremoved.docx 